\title{
Mastite subclínica causada por Staphylococcus aureus: custo-benefício da antibioticoterapia de vacas em lactação
}

[Subclinical mastitis caused by Staphylococcus aureus: cost benefit analysis of antibiotic therapy in lactating cows]

\author{
L.F. Zafalon ${ }^{1}$, A. Nader Filho ${ }^{2}$, J.V. Oliveira ${ }^{3}$, F.D. Resende ${ }^{3}$ \\ ${ }^{1}$ Embrapa Pecuária Sudeste \\ Rodovia Washington Luiz, Km 234, Caixa Postal 339 \\ 13560-970 - São Carlos, SP \\ ${ }^{2}$ Faculdade de Ciências Agrárias e Veterinárias - UNESP - Jaboticabal, SP \\ ${ }^{3}$ Polo Regional de Desenvolvimento Tecnológico dos Agronegócios da Alta Mogiana - Colina, SP
}

\begin{abstract}
RESUMO
Avaliou-se a relação custo-benefício do tratamento da mastite subclínica bovina causada por Staphylococcus aureus. Foram selecionados 270 quartos mamários com mastite subclínica e sadios, divididos em quatro grupos de acordo com o estádio de lactação e o tratamento. $\mathrm{O}$ grupo 1 foi formado por animais entre 10 e 60 dias da lactação e tratados contra mastites; o grupo 2 incluiu animais entre 61 dias da lactação e dois meses antes da secagem e tratados contra mastite; o grupo 3 foi formado por animais entre 10 e 60 dias da lactação, não tratados contra mastite; e o grupo 4 foi formado por animais entre 61 dias em lactação e dois meses antes da secagem, não tratados. O tratamento foi realizado pela infusão intramamária de $150 \mathrm{mg}$ de gentamicina, uma vez ao dia. A reavaliação foi efetuada após 30 dias. Para os cálculos dos custos com o tratamento, foram considerados uma prevalência de $S$. aureus de $5 \%$ e os gastos com medicamento, descarte do leite, antibiograma e mão-de-obra. Observou-se redução de $2 \% \mathrm{e}$ $14 \%$ das receitas nos grupos 1 e 2 , respectivamente, quando comparada com as receitas obtidas antes do tratamento, demonstrando ser economicamente inviável o tratamento da mastite subclínica bovina causada por $S$. aureus, durante a lactação.
\end{abstract}

Palavras-chave: bovino, mastite subclínica, tratamento, antibiótico, Staphylococcus aureus, custos

\begin{abstract}
Economic evaluation of the treatment bovine subclinical mastitis caused by S. aureus was evaluated. Two hundred and seventy udder quarters with or without subclinical mastitis were distributed into four groups, in conformity to lactational stage and treatments. Group 1 included animals treated between 10 and 60 days of lactation; group 2 included animals treated from 61 days of lactation to two months before drying; group 3 included animals no treated between 10 and 60 days of lactation; group 4 included animals no treated from 61 days of lactation to two months before drying. Treatment with gentamicin (150mg) was accomplished by intramammary doses, once a day, after performing sensitivity tests. The mammary quarters were re-evaluated after 30 days. The costs with the treatment were calculated considering a S. aureus prevalence of 5\% as well as expenses with antibiotic, milk disposal, tests of drug sensitivity and workload. There was loss of income of $2 \%$ and $14 \%$ in the groups 1 and 2, respectively, when compared with the values before the treatment. In such case, the treatment of bovine subclinical mastitis caused by $S$. aureus in the lactation was economically unviable.
\end{abstract}

Keywords: subclinical mastitis, treatment, antibiotic, Staphylococcus aureus, costs

Recebido em 17 de agosto de 2006

Aceito em 20 de abril de 2007

E-mail: zafalon@cppse.embrapa.br 


\section{INTRODUÇÃO}

A mastite é causada por Staphylococcus aureus. Por ser uma doença altamente prejudicial aos rebanhos leiteiros, muitos estudos sobre essa doença são feitos, e programas de manejo tentam melhorar a saúde da glândula mamária. Esse microrganismo tem sido isolado com freqüência em quartos mamários investigados (Waage et al., 1999; Godden et al., 2002; Fagundes, Oliveira, 2004).

O S. aureus é capaz de causar infecções de longa duração, com tendência a se tornarem crônicas, com baixa taxa de cura e grande perda na produção de leite (Sabour et al., 2004). Vários fatores podem interferir na cura bacteriológica quando se utiliza a terapia com antibióticos, seja devido ao estágio da ocorrência da infecção ou à presença de bactérias em abscessos, além da incapacidade de defesa das células (Diniz et al., 1998).

O tratamento de vacas é mais efetivo com infusões de antibióticos no final da lactação e não ao longo dela. Todavia, a terapia da vaca seca parece não diminuir a contagem de células somáticas (CCS) do leite obtido durante a lactação seguinte. Estudos que investigam o tratamento de vacas com alta CCS durante a lactação indicaram redução do número de células somáticas, entretanto, esse aspecto favorável não resultou em ganhos financeiros (Shephard et al., 2000).

A diminuição da duração das infecções intramamárias constitui-se em importante objetivo dos programas de controle de mastites, meta que pode ser alcançada com a antibioticoterapia realizada durante a lactação. Este trabalho teve os objetivos de estudar a relação custo-benefício do tratamento da mastite subclínica causada por $S$. aureus, realizado durante a lactação, e avaliar os efeitos do tratamento sobre as taxas de cura e CCS.

\section{MATERIAL E MÉTODOS}

Utilizaram-se animais com produção de leite em torno de 10 litros por ordenha, acompanhados durante dois anos, de maio de 2000 a maio de 2002, em uma fazenda experimental de instituição de pesquisa da região de Barretos, estado de São Paulo. A população bovina era constituída por vacas do grupo genético $7 / 8 \mathrm{da}$ raça Holandesa, todas submetidas à ordenha mecânica uma vez ao dia. Durante o período de estudo, a população bovina manteve-se em torno de 40 vacas em lactação.

Foram selecionados, de forma aleatória, 135 quartos mamários de vacas que se encontravam entre a segunda e a quinta lactações, cujas amostras de leite reagiram ao California Mastitis Test (CMT) e/ou foram positivas ao teste de condutividade elétrica, realizado com medidor portátil Mas-d-tec ${ }^{1}{ }^{1}$, nos quais foi realizado o isolamento de $S$. aureus (Microbiological..., 1990; Holt et al., 1994). Do total de quartos infectados por S. aureus, 67 foram tratados e 68 não o grupo-controle.

Selecionaram-se, ainda, 135 quartos mamários negativos às referidas provas e ao exame microbiológico, contralaterais àqueles com mastite subclínica, de modo a totalizar 270 quartos mamários, com a finalidade de comparar os valores de produção e a CCS do leite dos quartos doentes tratados e não tratados com os seus homólogos.

Os quartos mamários foram distribuídos em quatro grupos, de acordo com o estádio da lactação, no momento da colheita das amostras de leite: o grupo 1 foi constituído por 19 quartos, tratados contra mastites, de vacas entre 10 e 60 dias de lactação; o grupo 2, por 48 quartos, tratados contra mastites, de vacas entre 61 dias da lactação até dois meses antes da secagem; o grupo 3 por 14 quartos, não tratados, de vacas entre 10 e 60 dias de lactação; e o grupo 4 por 54 quartos, não tratados, de vacas entre os 61 dias em lactação até dois meses antes da secagem. A divisão dos estádios de lactação foi realizada de acordo com as recomendações de Cullen (1968) e Van Horn e Wilcox (1992). O número reduzido de animais selecionados nos dois meses que antecederam a secagem impossibilitou a realização do estudo no período final da lactação.

As amostras de leite dos quartos mamários selecionados foram submetidas às contagens de células somáticas de acordo com o método modificado de Prescott e Breed (National..., 1968), sendo a determinação feita por contagem

${ }^{1}$ Jeffco Internacional LTDA - Tautanga - Nova Zelândia 
direta em microscópio óptico em objetiva de imersão. As pesagens do leite foram realizadas após a ordenha completa de cada quarto mamário selecionado, tratados ou não, e dos respectivos quartos mamários contralaterais. Utilizou-se um dispositivo que, ao ser acoplado aos copos da ordenhadeira mecânica, permitia a obtenção individualizada do leite oriundo de cada quarto mamário. As pesagens foram realizadas durante duas ordenhas consecutivas e em duas ocasiões distintas - no momento do diagnóstico e 30 dias após a realização dos tratamentos. Nas vacas não tratadas, a pesagem era realizada no momento do diagnóstico e trinta dias após. A produção de leite dos quartos mamários era calculada pela média aritmética de dois dias consecutivos de pesagens.

A escolha do princípio ativo utilizado nos tratamentos dos quartos selecionados fundamentou-se em testes de suscetibilidade in vitro (Bauer et al., 1966), realizados com as estirpes de $S$. aureus frente a 12 antimicrobianos: gentamicina $(30 \mu \mathrm{g})$, amicacina $(30 \mu \mathrm{g})$, penicilina (10UI), oxacilina $(1 \mu \mathrm{g})$, tetraciclina $(30 \mu \mathrm{g})$, cefalotina $(30 \mu \mathrm{g}), \quad$ ampicilina $(10 \mu \mathrm{g})$, eritromicina $(15 \mu \mathrm{g})$, sulfazotrim $(25 \mu \mathrm{g})$ e vancomicina $(30 \mu \mathrm{g})$.

Os tratamentos foram realizados após o término da ordenha, durante três dias consecutivos, sendo utilizada a dose por infusão intramamária de $150 \mathrm{mg}$ de gentamicina ${ }^{2}$ uma vez ao dia. Foram considerados curados os quartos mamários cujas amostras de leite, colhidas em duplicatas, mostraram-se negativas ao isolamento de $S$. aureus, ao Mas-d-tec ${ }^{\circledR}$ e ao CMT, após 30 dias do tratamento.

Todos os cálculos foram efetuados considerandose a prevalência da mastite subclínica causada por $S$. aureus igual a $5 \%$ dos quartos, porcentagem obtida após visita prévia à propriedade. Assim, para o cálculo dos custos dos tratamentos, obteve-se um valor médio (R\$0,47/US\$ 0,16) para o litro de leite (Milkpoint, 2004), um valor unitário médio (R\$3,20/US\$ 1,10) para o antibimicrobiano utilizado e um valor unitário médio (R\$25,00/US\$ 8,62) para os testes de antibiograma. Foram considerados, ainda, intervalo de tempo, três dias, para a execução do

\footnotetext{
${ }^{2}$ Gentocin $^{\circledR}$ - Schering-Plough - Cotia, SP
}

tratamento, período de carência, quatro dias, do medicamento utilizado, assim como os gastos com mão-de-obra fundamentados no salário mensal (R\$ 300,00/US\$103,45) pago em abril de 2004 para um trabalhador rural (Instituto..., 2004).

As receitas mensais obtidas com o leite produzido, antes e depois da utilização do antibiótico, foram calculadas a partir das fórmulas:

$\mathrm{R}_{1}=\left(\mathrm{n}_{1} \times \mathrm{p}_{1} \times \mathrm{V}_{\mathrm{L}} \times 30^{\mathrm{a}}\right)+\left(\mathrm{n}_{2} \times \mathrm{p}_{2} \times \mathrm{V}_{\mathrm{L}} \times 30^{\mathrm{a}}\right) \mathrm{e}$

$R_{2}=\left(n_{1} \times p_{3} \times V_{L} \times 30^{a}\right)+\left(n_{2} \times p_{4} \times V_{L} \times 30^{a}\right), e m$ que:

$\mathrm{R}_{1}$ é receita obtida antes do tratamento; $\mathrm{R}_{2}$ a receita obtida após o tratamento; $\mathrm{n}_{1}$, o número de quartos sadios de acordo com a prevalência de $S$. aureus (152 quartos); $\mathrm{p}_{1}$, a produção média dos quartos mamários sadios, antes do tratamento; $\mathrm{V}_{\mathrm{L}}$, o valor médio pago ao produtor por um litro de leite $\mathrm{C} ; \mathrm{n}_{2}$, o número de quartos com mastite subclínica por $S$. aureus, de acordo com a prevalência do microrganismo, oito quartos; $\mathrm{p}_{2}$, a produção média dos quartos mamários doentes, antes do tratamento; $\mathrm{p}_{3}$, a produção média dos quartos mamários sadios, depois do tratamento; $\mathrm{p}_{4}$, a produção média dos quartos mamários doentes, depois do tratamento e $30^{\mathrm{a}}$ corresponde a 30 dias.

A variação porcentual $\left(V_{P}\right)$ entre as receitas antes e depois do tratamento foi obtida após o desconto dos custos com o tratamento.

Os custos com mão-de-obra foram obtidos a partir de um coeficiente técnico aplicado ao salário modal de um trabalhador rural mensalista segundo valores de abril de 2004. Esse coeficiente foi calculado a partir da carga horária mensal de trabalho igual a 220 horas. Para o cálculo, utilizaram-se: o tempo para a esgota de cada animal, 15 minutos, multiplicado pelo número de animais, oito, e pelo número de dias de esgota dos animais, seis; o tempo para a higienização das mãos do funcionário e dos tetos dos animais, um minuto, multiplicado pelo número de quartos mamários tratados, oito, e pelo número de dias de tratamento, três; e o tempo para a infusão do medicamento $\mathrm{e}$ massagem do úbere após o tratamento, um minuto, multiplicado pelo número de quartos mamários tratados, oito, e pelo número de dias 
de tratamento, três. Foram utilizadas 12,8 horas com o tratamento, empregando-se um coeficiente técnico igual a 0,0582 , obtido por regra de três simples. Aos custos foram adicionados os valores referentes aos encargos sociais (Tab. 1).

Tabela 1. Valores de referência para a análise dos custos com o tratamento da mastite subclínica por $S$. aureus durante a lactação

\begin{tabular}{lc}
\hline Fator & Valores (US\$) (a) \\
\hline - Custos com medicamento (b) & 26,40 \\
- Custos do antibiograma (b) & 68,96 \\
- Custos com mão-de-obra (mais encargos sociais) (b) & 8,61 \\
- Custos com descarte do leite - grupo 1 & 75,65 \\
- Custos com descarte do leite - grupo 2 & 71,88 \\
\hline (a): US\$ 1.00 = R\$ 2,90 (setembro de 2004); (b): valores para ambos os grupos tratados. Grupo 1= 19 quartos mamários de vacas \\
entre 10 e 60 de lactação; grupo 2= 48 quartos mamários de vacas entre 61 dias de lactação até 60 dias meses antes da secagem.
\end{tabular}

Para os custos com o leite descartado, utilizou-se a fórmula:

$G_{2}=\left[P_{1}+\left(P_{2} \times 3^{a}\right)\right] \times N \times D \times V_{L}$, em que:

$\mathrm{P}_{1}$ é a produção média do quarto mamário com mastite subclínica; $\mathrm{P}_{2}$, a produção média do quarto mamário sadio; $\mathrm{N}$, o número de animais doentes, oito; D, o número de dias em que o leite foi descartado, seis; $\mathrm{V}_{\mathrm{L}}$, o valor médio pago ao produtor por um litro de leite $\mathrm{C}^{\mathrm{a}}$ e o número de quartos mamários sadios, obedecendo-se à condição de um quarto mamário infectado por animal.

Os custos com o antibiótico utilizado foram obtidos pela multiplicação do preço do antibiótico pelo número de quartos tratados, oito, e pelo número de dias de tratamento, três. Os custos com a realização do antibiograma foram obtidos pela multiplicação do preço de cada antibiograma, multiplicado pelo número de quartos tratados (Tab. 1). Os mesmos cálculos foram efetuados nos quartos mamários sem tratamento e que serviram de controle. Neste caso, não houve o desconto dos custos com o tratamento na obtenção da variação porcentual entre as receitas. Os valores de referência utilizados para a análise dos custos encontram-se na Tab. 1.

Para análise da CCS e da produção de leite, utilizou-se o teste $\mathrm{t}$ para amostras pareadas, em que foram comparados os quartos mamários tratados e não tratados com seus respectivos contralaterais sadios, controlando, assim, possíveis variações individuais entre os animais. O teste do qui-quadrado foi usado para verificar se as taxas de cura e de recuperação espontânea foram diferentes nos grupos estudados, de acordo com as fases de lactação (Sampaio, 1998).

\section{RESULTADOS E DISCUSSÃO}

A Tab. 2 apresenta os resultados referentes à CCS antes do tratamento. Os valores médios de CCS das amostras de leite dos quartos mamários com mastite subclínica das vacas inseridas nos grupos 1 e 2, respectivamente, foram de $702.000 / \mathrm{ml}$ e de $397.000 / \mathrm{ml}$, sendo, portanto, $1.276,5 \%$ e $868,3 \%$ mais elevados que os observados nas amostras dos quartos mamários sadios. Após o tratamento, os valores médios das CCS foram reduzidos para 142.000 e 95.000 células/ml, respectivamente.

Tabela 2. Valores médios da contagem de células somáticas (CCS) de quartos mamários tratados e não tratados com gentamicina e quartos sadios

\begin{tabular}{|c|c|c|c|c|c|}
\hline \multirow{3}{*}{ Condição } & & \multicolumn{4}{|c|}{$\operatorname{CCS}\left(\times 10^{3} / \mathrm{ml}\right)$} \\
\hline & & \multicolumn{2}{|c|}{ Quartos infectados por S. aureus } & \multicolumn{2}{|c|}{ Quartos sadios } \\
\hline & & Dia zero & Dia 30 & Dia zero & Dia 30 \\
\hline Com tratamento & Grupo 1 (tratado) & $702 *$ & $142 *$ & 51 & 36 \\
\hline Com tratamento & Grupo 2 (tratado) & $397 *$ & $95^{\mathrm{ns}}$ & 41 & 59 \\
\hline Sem tratamento & Grupo 3 (não tratado) & $297 *$ & $303^{\mathrm{ns}}$ & 39 & 68 \\
\hline Sem tratamento & Grupo 4 (não tratado) & $490 *$ & $635^{*}$ & 39 & 57 \\
\hline
\end{tabular}

significativas em relação aos quarto sadios $(\mathrm{P}<0,05)$; ns $=$ não significativo $(\mathrm{P}>0,05)$. 
Os valores da CCS do leite das vacas dos grupos 3 e 4 foram, respectivamente, de $297.000 / \mathrm{ml}$ e de $490.000 / \mathrm{ml}, 661,5 \%$ e $1.257 \%$ mais elevados que os valores observados nas amostras dos quartos sadios. Decorridos 30 dias, os valores da CCS foram de $303.000 / \mathrm{ml}$ e $635.000 / \mathrm{ml}$, respectivamente, para o leito dos grupos 3 e 4, sendo, portanto, observada a elevação da CCS em ambos os grupos estudados.

Segundo Sol et al. (1994, 1997), quanto maior o número de células somáticas no momento do tratamento, menor parece ser o sucesso da terapia intramamária durante a lactação. Allore et al. (1998) demonstraram que o tratamento durante a lactação, em conjunto com estratégias preventivas e a terapia da vaca seca reduziram: a CCS do leite de conjunto, o número de meses com contagem superior a 500.000 células $/ \mathrm{ml}$ e o número de descartes devido à mastite. A influência negativa da elevada CCS no leite de uma ou mais vacas sobre a CCS do leite de conjunto pode influenciar a tomada de decisão sobre a realização do tratamento durante a lactação e, conseqüentemente, o seu possível efeito positivo na redução da CCS. Contudo, outros fatores devem ser considerados no tratamento dos animais, como a idade, por exemplo.

A Tab. 3 apresenta os valores médios da produção láctea dos quartos mamários tratados e não tratados, e dos quartos sadios. Verificou-se pequeno aumento da produção dos quartos mamários com mastite subclínica (tratados) do grupo 1 (2.150g versus $2.186 \mathrm{~g}$ ) e dos quartos sadios dos grupos 1 (2.568g versus $2.757 \mathrm{~g}), 3$ $(2.850 \mathrm{~g}$ versus $2.878 \mathrm{~g})$ e $4(2.105 \mathrm{~g}$ versus $2.121 \mathrm{~g})$. Verificou-se, também, pequena redução da produção dos quartos mamários com mastite subclínica (tratados) do grupo 2 (1.948g versus $1.809 \mathrm{~g}$ ), assim como dos quartos não tratados dos grupos 3 (2.354g versus 2.296g), 4 (1.575g versus $1.533 \mathrm{~g}$ ) e dos quartos sadios do grupo 2 (2.471g versus $2.339 \mathrm{~g}$ ).

Tabela 3. Valores médios das produções lácteas de quartos mamários tratados/não tratados com gentamicina e quartos sadios

\begin{tabular}{|c|c|c|c|c|c|c|}
\hline & & \multirow{3}{*}{$\mathrm{n}$} & \multicolumn{4}{|c|}{ Produção (g) } \\
\hline & & & \multicolumn{2}{|c|}{ Quartos infectados por $S$. aureus } & \multicolumn{2}{|c|}{ Quartos sadios } \\
\hline & & & Dia zero & Dia 30 & Dia zero & Dia 30 \\
\hline Com tratamento & Grupo 1 tratado (1) & 38 & $2150^{\mathrm{ns}}$ & $2186^{*}$ & 2568 & 2757 \\
\hline Com tratamento & Grupo 2 tratado (2) & 96 & $1948 *$ & $1809 *$ & 2471 & 2339 \\
\hline Sem tratamento & Grupo 3 não tratado (1) & 28 & $2354 *$ & $2296^{*}$ & 2850 & 2878 \\
\hline Sem tratamento & Grupo 4 não tratado (2) & 108 & $1575^{*}$ & $1533^{*}$ & 2105 & 2121 \\
\hline
\end{tabular}

(1): 10 a 60 dias pós-parto; (2): início do terceiro mês pós-parto até dois meses antes da secagem. * Diferenças significativas em relação aos quarto sadios $(\mathrm{p}<0,05)$, ns= não significativo $(\mathrm{P}>0,05)$.

O aumento da produção de leite dos quartos doentes e tratados do grupo 1 não pode ser considerado como um efeito positivo do tratamento durante a lactação, pois houve também aumento na produção dos quartos sadios do mesmo grupo. A produção dos quartos tratados foi significativamente menor que a dos quartos sadios.

Vários são os mecanismos propostos para explicar os danos que a mastite pode causar ao epitélio secretório da glândula mamária, dentre os quais citam-se a secreção de toxinas por bactérias, a liberação de enzimas lisossomais de neutrófilos degenerados ou ativos próximos ao tecido secretor e a diapedese de neutrófilos que atravessam o epitélio em direção aos alvéolos (Macdonald et al., 1994).
O tratamento da mastite subclínica realizado durante a lactação não foi capaz de determinar significativa elevação da produção de leite dos quartos tratados (Tab. 2 e 3). Todavia, os valores médios das CCS das amostras de leite dos quartos sadios situaram-se abaixo de 150.000 células/ml - quartos infectados dos grupos 1 e 2 , dia 30 , diferente dos quartos não tratados, cujos valores situaram-se acima de 300.000 células $/ \mathrm{ml}$, grupos 3 e 4 . Após o tratamento, não se observou diferença $(\mathrm{P}>0,05)$ entre os quartos mamários tratados e sadios do grupo 2 .

A Fig. 1 apresenta a distribuição das taxas de cura observadas entre os quartos com mastite subclínica tratados e não tratados. As taxas de cura obtidas entre os quartos mamários tratados dos animais dos grupos 1 e 2 foram de 79,0\% e $83,3 \%$, respectivamente. Salienta-se a 
possibilidade de existirem quartos mamários com recuperação espontânea dentre aqueles considerados curados pelo tratamento antimicrobiano.

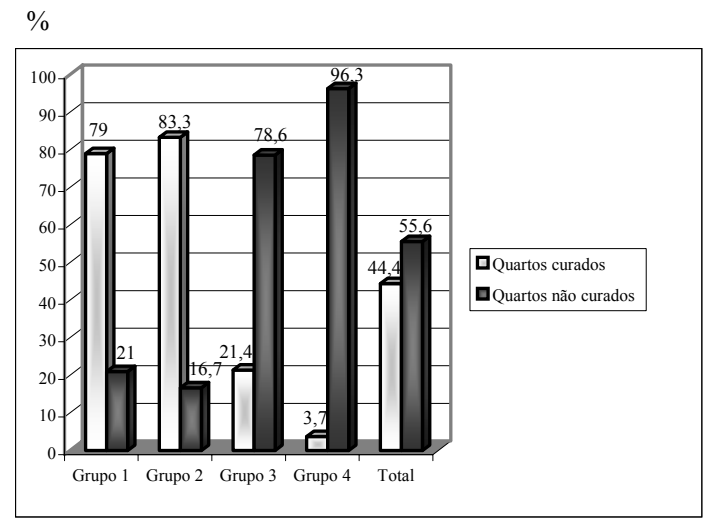

Figura 1. Taxas de cura (\%) de mastite subclínica por Staphylococcus aureus em quartos mamários tratados com gentamicina, grupos 1 e 2 , e sem tratamento, grupos 3 e 4 .

Costa et al. (1997) realizaram o tratamento de vacas com mastite subclínica com cefacetril, gentamicina e cloxacilina e encontraram altas taxas de cura microbiológica e/ou resultados traços ou negativos ao CMT $(78,6 \%, 86,1 \%$ e $95,4 \%$, respectivamente). Os estafilococos correspondiam a $33,6 \%$ dos agentes isolados antes do tratamento. Langoni et al. (1997) também obtiveram taxas de cura elevadas, $85,3 \%$ a $90,3 \%$, para a mastite subclínica causada por $S$. aureus e Streptococcus agalactiae, respectivamente, com a utilização de hidroiodeto de penetamato associado com a dihidroestreptomicina, sulfato de framicetina e prednisolona.

Reis et al. (2003) observaram redução de 57\%, $50 \%$ e $35,7 \%$ no isolamento de $S$. aureus após tratamento da mastite subclínica durante a lactação com cefacetril, em períodos que variaram desde 14 até 40 dias após o tratamento. Oliver et al. (2004), ao avaliarem a eficácia do ceftiofur aplicado, uma vez ao dia, na intramamária para $o$ tratamento durante a lactação da mastite subclínica, verificaram que a taxa de cura para o $S$. aureus foi de $36 \%$, com oito dias de tratamento pela administração intramamária uma vez ao dia.
O tipo de tratamento e outros fatores devem ser considerados na análise da cura bacteriológica, após o tratamento da mastite subclínica durante a lactação, como o número de lactações, a duração do tratamento, a idade do animal e o tipo de microrganismo envolvido na etiologia da doença (Deluyker et al., 2005). Devem, também, ser consideradas as características imunológicas do animal e a capacidade de $S$. aureus permanecer encapsulado no interior das células de defesa.

Segundo Owens et al. (2001), a prevalência de $S$. aureus foi aproximadamente duas vezes mais elevada em quartos mamários que apresentavam lesões. A presença de cortes ou outros tipos de lesões no quartos mamários pode interferir na resposta ao tratamento contra $S$. aureus.

Brito et al. (2001) relataram que as propriedades farmococinéticas do composto, incluindo solubilidade em lipídio, constante de dissociação e afinidade em se ligar à proteína, assim como a proporção ativa não ligada a outras substâncias no corpo do animal, determinam a sua capacidade de penetração e distribuição nos tecidos, sangue e leite.

Uma vez que não foram encontrados quaisquer tipos de lesões nos quartos tratados durante o período de estudo, e a gentamicina é considerada um princípio ativo de baixa absorção quando administrada por via intramamária, a adoção correta dos procedimentos terapêuticos, desde a esgota do quartos mamários até a maneira como foi realizada a infusão do medicamento, podem ter contribuído para as elevadas taxas de cura obtidas. Além disso, a dormência bacteriana, representada pela não multiplicação do $S$. aureus e o encapsulamento bacteriano, citados por Sears (2001), podem não ter ocorrido.

A glândula mamária é protegida por mecanismos de defesa primários e secundários. Os mecanismos de defesa primários são aqueles que previnem a entrada de patógenos para o interior da glândula e são associados com o canal do teto. Os secundários são mecanismos químicos, celulares e imunológicos, localizados no interior da glândula, como a lactoferrina, o sistemacomplemento, a lisozima e o sistema lactoperoxidase-tiocianato-peróxido de hidrogênio (Sordillo et al., 1997). 
Segundo Sol et al. (1997), o estímulo inflamatório determina uma reação local representada pela liberação, ativação e síntese de mediadores químicos e manifesta-se por alterações hemodinâmicas e hematológicas. A atuação desses mediadores dos mecanismos de defesa da glândula mamária pode ter contribuído para as altas taxas de cura dos quartos mamários infectados por $S$. aureus.

Segundo Shephard et al. (2000), 28 dentre 214 vacas tratadas experimentaram episódios clínicos de mastite uma semana após o tratamento. Acredita-se que a principal causa desses casos da doença foi a introdução de bactérias para o interior da glândula no momento do tratamento. Desse modo, há necessidade de conscientizar os produtores de leite da necessidade de esterilizar as cânulas intramamárias. Isso inclui preparação da glândula, maneira de inserção da cânula e higienização após o tratamento.

As taxas de recuperação espontânea em ambas as fases de lactação foram mais baixas que as encontradas por Soback et al. (1990), Nickerson et al. (1991) e Faria et al. (1996), que variaram de $33 \%$ a $48 \%$. Oliver et al. (2004) encontraram taxas de recuperação espontânea de 10,5\%.

As variações (\%) das receitas oriundas da produção de leite de quartos mamários tratados com gentamicina contra mastite subclínica por $S$. aureus e quartos mamários não tratados foram de $-2,1,-14,8,0,8$ e 0,6 para os grupos $1,2,3$ e 4, respectivamente.

Estes resultados referem-se às observações realizadas durante 30 dias, período em que não houve aumento de produção de leite, muito embora tenha ocorrido diminuição na CCS. Tais resultados discordam dos obtidos por Buragohain e Dutta (1994), que constataram aumento da produção de leite após o tratamento de vacas com mastite subclínica, especialmente naqueles animais que se encontravam no início lactação.

Essas variações das receitas foram positivas quando não se fez tratamento. Contudo, essa atitude pode favorecer a manutenção de fontes de infecção no rebanho, que podem acarretar, mais adiante, o comprometimento da qualidade e da quantidade de leite produzido na propriedade. A presença contínua de fontes de infecção pode acontecer quando quartos mamários são tratados e não curados, o que não interferiu na análise custo-benefício neste estudo.

Allore e Erb (1998) assinalaram que a terapia da mastite subclínica durante a lactação, quando utilizada com outros componentes de controle, proporciona menor ocorrência de casos clínicos. A possibilidade de cura depende da estirpe bacteriana ou do animal. Algumas amostras de $S$. aureus parecem ser mais sensíveis ao tratamento que outras e também algumas vacas recuperamse melhor, sejam elas tratadas ou não (Sol et al., 2000). A probabilidade de transmissão de $S$. aureus e o manejo da propriedade são fatores que podem influenciar na análise econômica do tratamento (Swinkels et al., 2005).

Segundo Zepeda et al. (1998), os benefícios de um programa de controle de mastite por $S$. aureus dependem, principalmente, da prevalência da enfermidade, do custo do tratamento e do prêmio pela redução da contagem de células somáticas.

Embora os autores citados tenham afirmado que a produção e o preço do leite têm pequeno impacto sobre o lucro líquido de um programa de controle de mastite estafilocócica, neste estudo verificou-se que quanto mais elevada a produção maiores seriam as perdas decorrentes do tratamento, especialmente aquelas relacionadas com a redução da produção e com o descarte do leite das vacas tratadas.

Não foi considerada uma possível premiação decorrente da melhoria da qualidade do leite obtido após o tratamento, pois os resultados médios das CCS referem-se a quartos individuais e não ao leite de conjunto. Segundo Swinkels et al. (2005), o tratamento durante a lactação pode ser economicamente viável quando a qualidade do leite é um componente significativo do produto ou quando casos clínicos ou a transmissão de microrganismos podem ser prevenidos. Entretanto, cuidados devem ser tomados para evitar o risco de resíduos de antimicrobianos no leite.

O uso da antibioticoterapia no controle da mastite subclínica durante a lactação e suas possíveis conseqüências deveriam ser estudadas em período superior a 30 dias. Desse modo, seria possível obter informações mais precisas sobre a variação da produção de leite, assim como da 
ocorrência ou não de reinfecções, importantes para o estudo da relação custo-benefício do tratamento.

\section{CONCLUSÕES}

O tratamento da mastite subclínica causada por $S$. aureus, durante a lactação, com gentamicina intramamária, ainda que com elevadas taxas de cura microbiológica, não resultou em aumento da produção de leite dos quartos tratados em comparação com a dos quartos sadios. $\mathrm{O}$ tratamento intramamário não traz benefícios econômicos com aumento de receita, mas reduz a CCS dos quartos tratados, e melhora a qualidade do leite.

\section{AGRADECIMENTOS}

Fundação de Amparo à Pesquisa do Estado de São Paulo (Fapesp) - Processo n ${ }^{0}$ 98/16087-6; profa. Maria Madalena Zocoller Borba Departamento de Economia Rural (FCAVJ/UNESP); prof. João Ademir de Oliveira - Departamento de Ciências Exatas (FCAVJ/UNESP).

\section{REFERÊNCIAS BIBLIOGRÁFICAS}

ALLORE, H.G.; ERB, H.N. Partial budget of the discounted annual benefit of mastitis control strategies. J. Dairy Sci., v.81, p.2280-2292, 1998.

ALLORE, H.G.; ERB, H.N.; SCHRUBEN, L.W. et al. A simulation of strategies to lower bulk tank somatic cell count below 500,000 per milliliter. J. Dairy Sci., v.81, p.694-702, 1998.

BAUER, A.W.; KIRK, M.M.; SHERRIN, J.D. Antibiotics susceptibility testing by standardized single disk method. Am. J. Clin. Pathol., v.45, p.493-496, 1966.

BRITO, M.A.V.P.; BRITO, J.R.F.; SILVA, M.A.S. et al. Concentração mínima inibitória de dez antimicrobianos para amostras de Staphylococcus aureus isoladas de infecção intramamária bovina. Arq. Bras. Med. Vet. Zootec., v.53, p.531-537, 2001.
BURAGOHAIN, J.; DUTTA, G.N. A note on the efficacy of treatment during lactation for the control of bovine mastitis. Indian Vet. J., v.71, p.504-504, 1994.

CULLEN, G.A. Cell count throughout lactation. Vet. Rec., v.38, p.125-128, 1968.

DELUYKER, H.A.; VAN OYE, S.N.; BOUCHER, J.G. Factors affecting cure and somatic cell count after pirlimycin treatment of subclinical mastitis in lactating cows. J. Dairy Sci., v.88, p.604-614, 2005.

DINIZ, M.A.P.R.; BRANDÃO, S.C.C.; FARIA, E. et al. Tratamento de mastite subclínica e clínica, em vacas lactantes, com ácido acetilsalicílico, mastenzin e associação mastenzin com ácido acetilsalicílico. Hora Vet., n.18, p.27-33, 1998.

FAGUNDES, H.; OLIVEIRA, C.A.F. Infecções intramamárias causadas por Staphylococcus aureus e suas implicações em saúde pública. Ciên. Rural, v.34, p.1315-1320, 2004.

FARIA, J.E.; FIGUEIREDO, J.B.; FACURY JÚNIOR, E.J. et al. Infecção estafilocócica em vacas no final da lactação e no início da seguinte. Arq. Bras. Med. Vet. Zootec., v.48, p.533-541, 1996.

GODDEN, S.M.; JANSEN, J.T.; LESLIE, K.E. et al. The effect of sampling time and sample handling on the detection of Staphylococcus aureus in milk from quarters with subclinical mastitis. Can. Vet. J., v.43, p.38-42, 2002.

HOLT, J.G.; KRIEG, N.R.; SNEATH, P.H.A. et al. Gram-positive cocci. In: BERGEY'S MANUAL OF DETERMINATIVE BACTERIOLOGY. 9.ed. Baltimore: Williams \& Wilkins, 1994. p.544-551.

INSTITUTO de Economia Agrícola. Salários rurais, por categoria, estado de São Paulo, abril de 2004. Disponível em: $<$ http://www.iea.sp.gov.br>. Acessado em: 17 jul. 2004.

MACDONALD, E.A.; XIA, L.; MONARDES, $H$. et al. Neutrophil function in vitro: diapedesis and phagocytosis. J. Dairy Sci., v.77, p.628-638, 1994.

MICROBIOLOGICAL procedures for the diagnosis of bovine udder infection. Arlington, VA: The National Mastitis Council, 1990. 34p. 
MILKPOINT. Cotações de leite. 2004. Scot consultoria Disponível em: $<$ http://www.milkpoint.com.br>. Acessado em: 17 jul. 2004.

NATIONAL MASTITIS COUNCIL. Subcommittee On Screening Tests. Direct microscopic somatic cell count in milk. J. Milk and Food Technol., v.31, p.350-354, 1968.

NICKERSON, S.C.; OWENS, W.E.; BODDIE, R.L. Progress in the development of a vaccine to control mastitis. Louisiana Agric., v.34, p.20-22, 1991.

OLIVER, S.P.; GILLESPIE, B.E.; HEADRICK, S.J. et al. Efficacy of extended ceftiofur intramammary therapy for treatment of subclinical mastitis in lactating dairy cows. $J$. Dairy Sci., v.87, p.2393-2400, 2004.

OWENS, W.E.; NICKERSON, S.C.; BODDIE, R.L. et al. Prevalence of mastitis in dairy heifers and effectiveness of antibiotic therapy. J. Dairy Sci., v.84, p.814-817, 2001.

REIS, S.R.; SILVA, N.; BRESCIA, M.V. Antibioticoterapia para controle da mastite subclínica de vacas em lactação. Arq. Bras. Med. Vet. Zootec., v.55, p.651-658, 2003.

SABOUR, P.M.; GILL, J.J.; LEPP, D. et al. Molecular Typing and Distribution of Staphylococcus aureus Isolates in Eastern Canadian Dairy Herds. J. Clin. Microbiol., v.42, p.3449-3455, 2004.

SAMPAIO, I.B.M. Estatística aplicada à experimentação animal. Belo Horizonte: Fundação de Ensino e Pesquisa em Medicina Veterinária e Zootecnia, 1998. 221p.

SEARS, P.M. Staphylococcus aureus mastitis. In: ANNUAL MEETING, NATIONAL MASTITIS COUNCIL, PART 1 OF 7, 32., Disponível em: $<$ http://www.uwrf.edu/biotech/workshop/activity /act16/annexd2.htm>. Acessado em: 22 jun. 2001.

SHEPHARD, R.W.; MALMO, J.; PFEIFFER, D.U. A clinical trial to evaluate the effectiveness of antibiotic treatment of lactating cows with high somatic cell counts in their milk. Austr. Vet. J., v.78, p.763-768, 2000.

SOBACK, S.; ZIV, G.; WINKLER, M. et al. Systemic dry cow therapy - a preliminary report. J. Dairy Sci., v.73, p.661-666, 1990.

SOL, J.; SAMPIMON, O.C.; BARKEMA, H.W. et al. Factors associated with cure after therapy of clinical mastitis caused by Staphylococcus aureus. J. Dairy Sci., v.83 p.278-284, 2000.

SOL, J.; SAMPIMON, O.C.; SNOEP, J.J. et al. Factors associated with bacteriological cure after dry cow treatment of subclinical Staphylococcal mastitis with antibiotics. J. Dairy Sci., v.77, p.75-79, 1994.

SOL, J.; SAMPIMON, O.C.; SNOEP, J.J. et al. Factors associated with bacteriological cure during lactation after therapy for subclinical mastitis caused by Staphylococcus aureus. J. Dairy Sci., v.80, p.2803-2808, 1997.

SORDILLO, L.M.; SHAFER-WEAVER, K.; DeROSA, D. Immunobiology of the mammary gland. J. Dairy Sci., v.80, p.1851-1865, 1997.

SWINKELS, J.M.; ROOIJENDIJK, J.G.A.; ZADOKS, R.N. et al. Use of a parcial budgeting to determine the economic benefits of antibiotic treatment of chronic subclinical mastitis caused by Streptococcus uberis or Streptococcus dysgalactiae. J. Dairy Res., v.72, p.75-85, 2005.

VAN HORN, H.H.; WILCOX, C.J. Monitoring milk quality and udder health. In: (Eds.). Large Dairy Herd Management. Champaign, 1992. p.475-86.

WAAGE, S.T.; MORK, A.; ROROS, D. et al. Bacteria associated with clinical mastitis in dairy heifers. J. Dairy Sci., v.82, p.712-719, 1999.

ZEPEDA, L.; BUELOW, K.L.; NORDLUND, $\mathrm{K}$.V. et al. A linear programming assessment of the profit from strategies to reduce the prevalence of Staphylococcus aureus mastitis. Prev. Vet. Med., v.33, p.183-193, 1998. 